\title{
Colonial iron in context: the Trianon slave shackle from Mauritius
}

\author{
Krish Seetah $^{1} \cdot$ Thomas Birch $^{2} \cdot$ Diego Calaon ${ }^{1,3} \cdot$ Saša Čaval ${ }^{1,4}$
}

Received: 5 March 2015 / Accepted: 30 September 2015 / Published online: 13 October 2015

(C) Springer-Verlag Berlin Heidelberg 2015

\begin{abstract}
In 2009, part of a 'slave shackle' was recovered from archaeological investigations at Trianon, an indentured labourer site on Mauritius dated from the beginning of the nineteenth century. This paper presents the results of a metallurgical assessment of the artefact, thought to represent colonial ironwork, a category that has hitherto remained understudied. The results are incorporated into the wider archaeological and historical evidence from Trianon, highlighting the value of studying colonial ironwork in context.
\end{abstract}

Keywords Colonial $\cdot$ Shackle $\cdot$ Iron $\cdot$ Indentured labour · Slavery

\section{Introduction}

During fieldwork surveys in 2009 at Trianon, a small Dshaped ferrous artefact was recovered, sparking considerable interest amongst the field archaeologists (Seetah 2010a). The find was identified as part of a shackle, a type used in

Thomas Birch

birch@em.uni-frankfurt.de

1 Department of Anthropology, Stanford University, Main Quad, 450 Serra Mall, Stanford, CA 94305, USA

2 Instittut für Archäologische Wissenschaften, Abt. II, Goethe-Universität Frankfurt am Main, Norbert-Wollheim-Platz 1, 60629 Frankfurt am Main, Germany

3 Dipartimento di Scienze Amientali, Informatica e Statistica (DAIS), Università Ca' Foscari Venezia, Dorsoduro 3246, 30123 Venezia, Italy

4 Slovenian Academy of Sciences and Arts, Institute of Anthropological and Spatial Studies, Scientific Research Centre, Novi trg 2, SI-1000 Ljubljana, Slovenia
Mauritius during the period of slavery, a relic of the island's turbulent past and its association with forced and free labour migrations. For the Indian Ocean in general, and this region specifically, we still have large gaps in our knowledge about the material culture of slaves and indentured labourers; 'modern-world' archaeology (Orser 2014) of this region lags far behind the Atlantic. Thus, this single artefact had the potential to provide much needed material evidence that could be informative at a number of levels. At the most basic, by studying its composition, the shackle would provide details as to the technological processes that were employed during its formation. If provenance could be established, there was the potential to reveal how certain aspects of trade, relating to metals specifically, were conducted between Europe and this colonial outpost and perhaps within the Indian Ocean world more generally.

At a local level, the shackle could help enrich our understanding of daily life for slaves (or possibly labourers, see below) on the island by adding an important piece of evidence to an otherwise impoverished repository of finds. At the present time, artefacts detailing slave/freed slave lifeways, specifically, are restricted to surface finds from Makak (ColwellChanthaphonh et al. 2014), materials recovered from the 'Old Cemetery' (Appleby et al. 2014; Seetah 2015a), both from Le Morne, as well as a few artefacts that are known of, but remain unstudied and unpublished, from sites such as Black River Gorges. The only other shackles recovered to date in Mauritius are exhibited at the Naval Museum in Mahebourg, unfortunately without their specific provenance (Fig. 1). These artefacts are associated with Manilla bronze tokens, slave-trade bracelets, recovered from The Speaker (1702) and Duoro (1843) shipwrecks. Thus, to our knowledge, and despite nearly 300 years of slavery and indenture, this shackle is the only such example recovered from terrestrial sites on Mauritius itself. The significance of this find, 
Fig. 1 Shackles from Mahebourg Museum, end of eighteenth to early nineteenth century (redrawn from original)
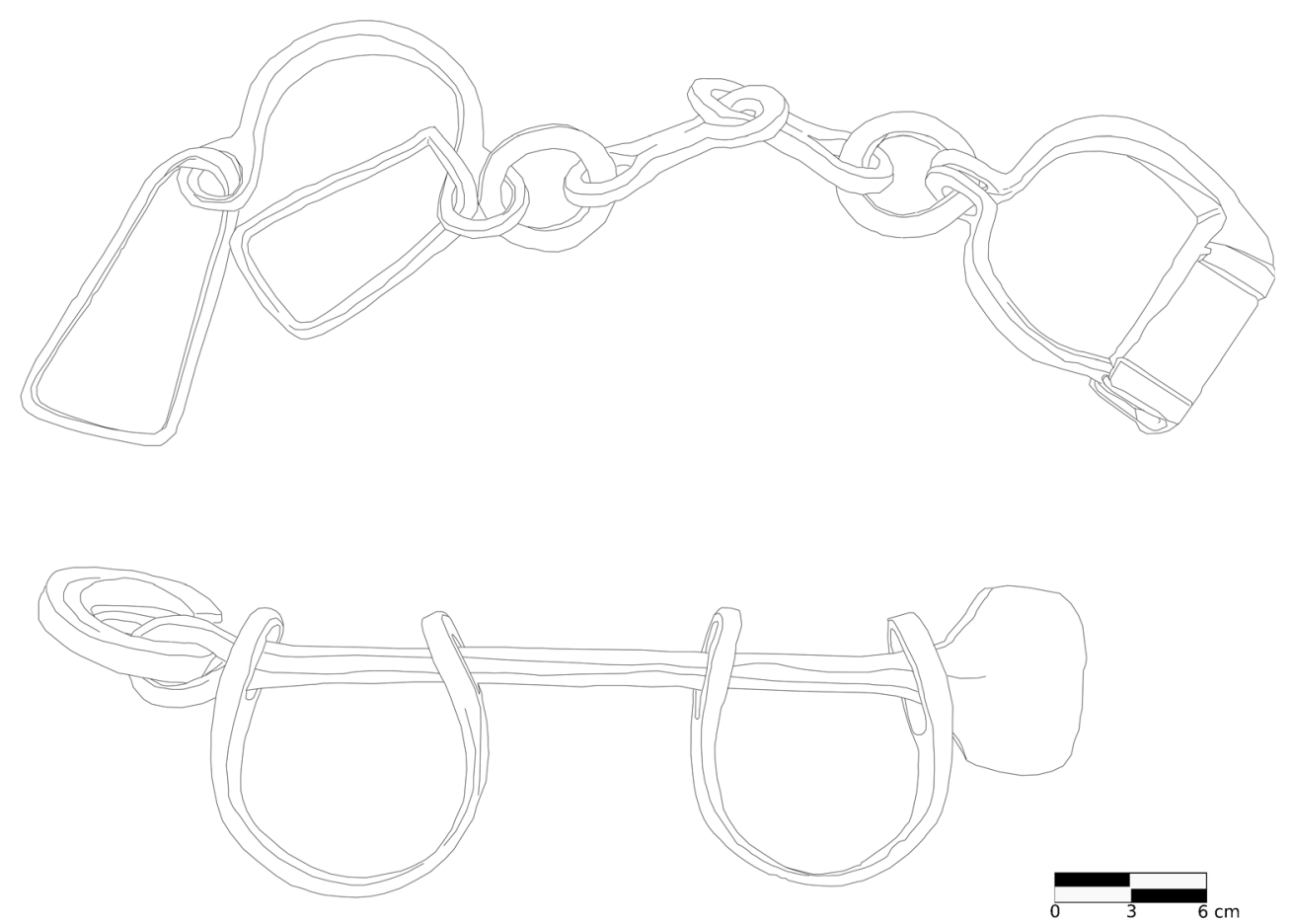

therefore, needs to be considered and contextualised against the paucity of such finds in this region as a whole and the fact that slavery in the Indian Ocean offers a significant comparative to the Atlantic model of forced labour.

This article focuses on metallurgical analysis as a first step to redressing a near-complete (to our knowledge) absence of this type of scientific assessment from historic archaeological sites in the southern-western Indian Ocean. This small metal object provided an opportunity to study an artefact that otherwise might have received little attention and is especially important considering the sensitive issues involved with this aspect of colonial archaeology (Gosden 2004). The artefact study presented here incorporates the results from metallographic and chemical analyses alongside the archaeological and historical context of Trianon, providing an insight into its technological origins and life history. The investigation of the find makes it possible to corroborate historical accounts and to assess the social relationships associated with slavery, and potentially, indentured labour.

While such evidence of human control is a poignant example of why abolition was necessary, of scientific interest are details of the production, manufacture and provisioning of raw materials that can be gleaned from this piece. This then begins to redress the imbalance mentioned above; indeed, the lack of an 'archaeology of slavery and indenture' formed the reason for the initial establishment of the Mauritian Archaeology and Cultural Heritage (MACH) project (Seetah 2015b). If we endeavour to further enable a post-colonial discourse, it is necessary to increase our familiarity with the material culture of slaves and indentured labourers.

\section{Trianon: an indentured labour camp}

The MACH project commenced in 2008, focused on the slave and indentured diasporas in the region (Seetah 2010b; Seetah et al. 2011). Between 2009 and 2011, a systematic programme of research focused on Trianon (Fig. 2), a National Heritage Monument inscribed in 1974, for which a detailed field report ${ }^{1}$ has been written. It houses the best preserved example of an indentured barracks (Fig. 3), small rectangular rooms arranged in long terrace fashion and typical throughout the colonial empire (Peerthum 2010). Surveys, including magnetometry and ground-penetrating radar (GPR), were undertaken in 2009 and 2010, followed by two seasons of excavation that revealed numerous features detailing both the lifeways of the plantation workers and organisation of the sugar estate (Calaon et al. 2012).

In terms of contextualising the shackle, we should not be distracted by the fact that for the majority of the time that Trianon functioned as a plantation, it was largely populated by indentured, i.e. contract, labourers. As the name suggests, this form of labour provision was consensual (Drescher 2004) and in theory, should not have required the use of shackles. Trianon was one of the last sugar estates to have been established on the island. Granted as a concession to Jean Baptiste Giblot Ducray

\footnotetext{
${ }^{1}$ The unpublished field report can be obtained from the author or from the Aapravasi Chat Trust: Seetah, K (2011) Trianon: Archaeological Investigations of an Indentured Barrack. Report commissioned by and prepared for the Aapravasi Ghat Trust Fund, Port Louis, Mauritius
} 
Fig. 2 Inset: Mauritius and its relation to continental Africa. Main: Mauritius with capital starred and site highlighted

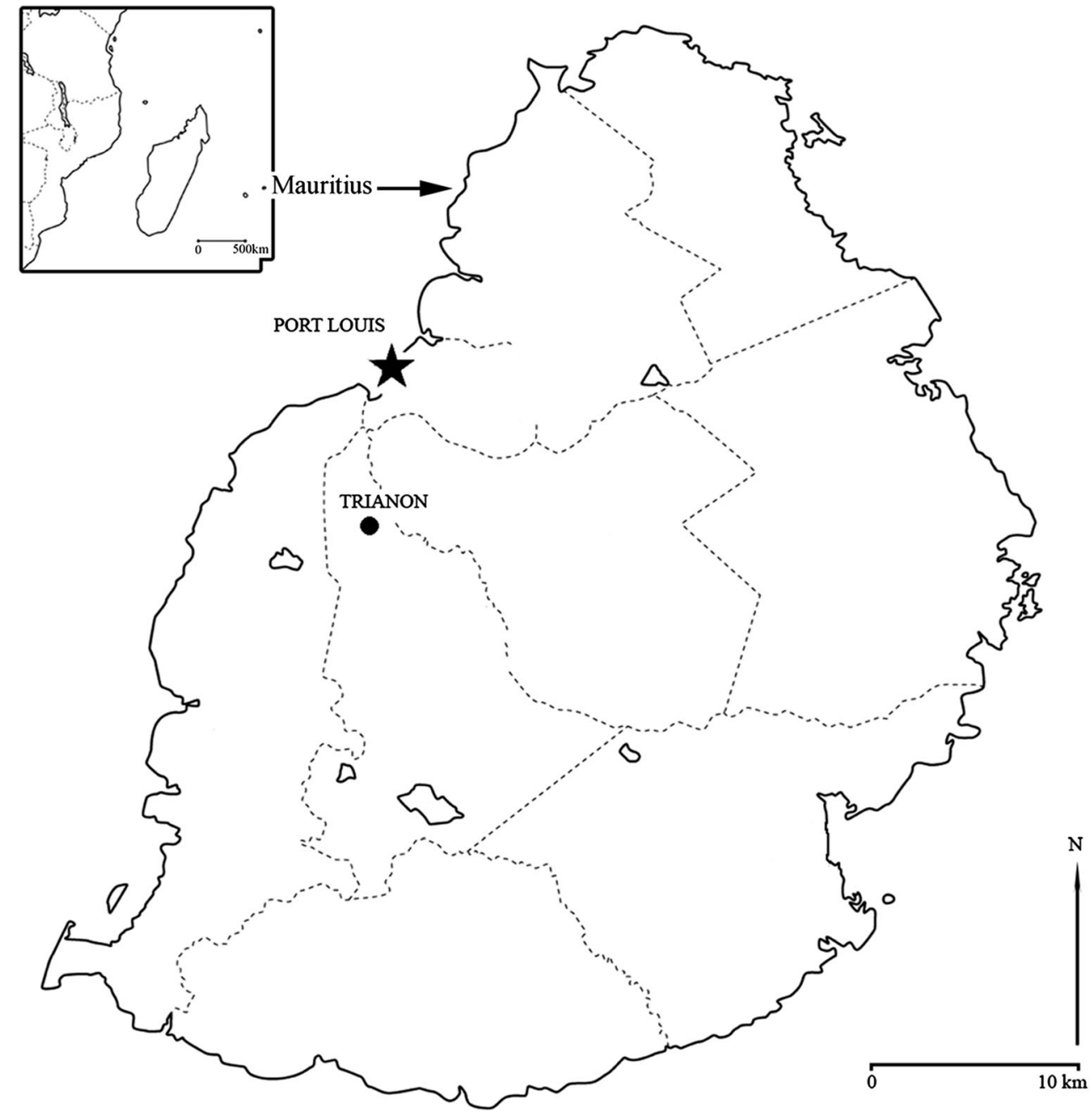

in 1730 (Rouillard 1979, 336), it became a functioning sugar estate in the first decade of the nineteenth century
(Rouillard 1979, 266). Thus, for some 25 years, slaves provided the workforce for sugar production.
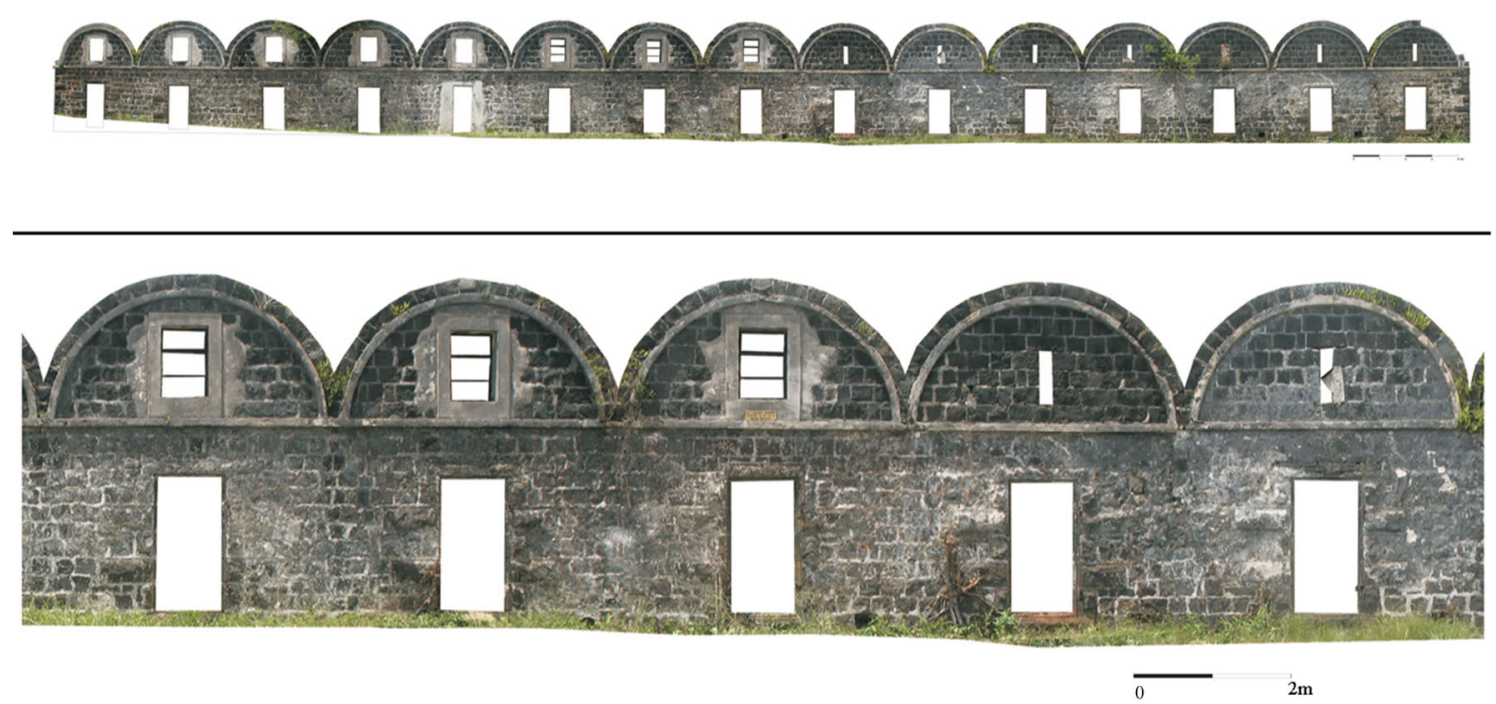

Fig. 3 Trianon barracks. Upper: photogrammetric representation of the entire row of barracks; lower detail of individual barracks 
An ongoing review of housing used for both slaves and indentured workers suggests that slaves were probably lodged in barrack style buildings, similar to the ones present in Trianon, and beside which the shackle was recovered (Fig. 4). Moreover, these barracks were used only as a dormitory, with meals eaten elsewhere, and privies located nearby. In contrast, the indentured workers showed a strong aversion to the stone barracks, considering them both impractical and unhealthy. The indentured labourers showed a distinct preference for wooden huts with thatched roofs, and they were often permitted to build their own dwellings from materials available on the sugar estates (Report Royal Commissioners of Immigrants 1875, 353 , n. 2098). Archival pictures reinforce this preference, illustrating this latter form of construction associated with labourers. Despite this, it seems evident that for Trianon, at least, the stone barracks were still used to house labourers (Report Royal Commissioners of Immigrants 1875, 205). However, by the second half of the nineteenth century, it appears that no new barracks were built in Mauritius, and this may be a direct consequence of the general preference that labourers had for thatch huts.

Fig. 4 The Trianon estate in the nineteenth century according the archaeological, historical and oral sources. Top: the topography of the estate in the second half of nineteenth century, with the localisation of the indentured labourer camp around the Mill and the Master's House. Below: the core area of the estate before 1835 , with location of the stone barracks and the shackle
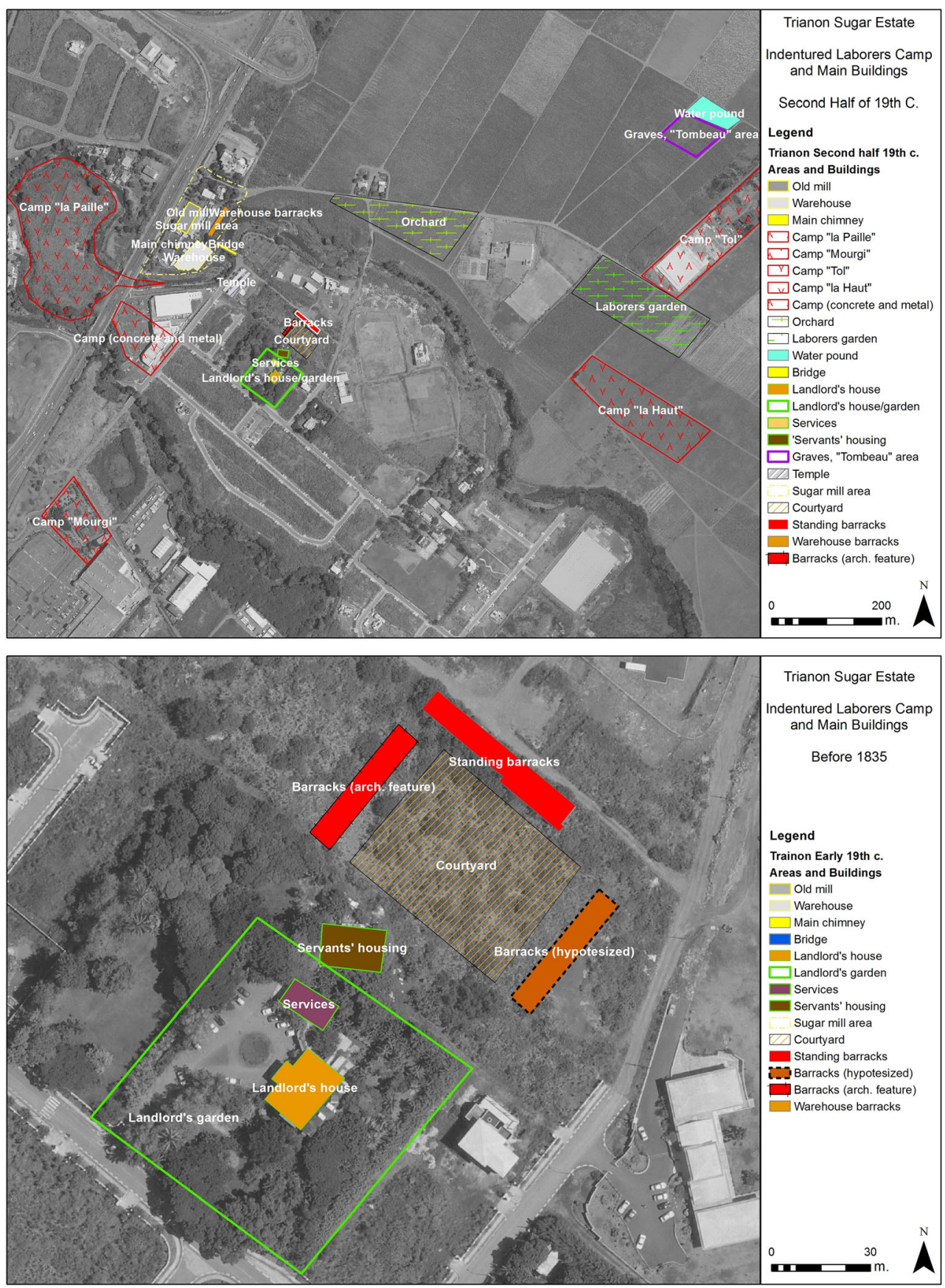
Although this was a surface find, there was little indication during subsequent excavations that the surrounding and underlying soils themselves had been re-deposited. Furthermore, only a small portion of the artefact was initially visible; the remainder was buried in the soil. Thus, the find appears to be associated with the barracks themselves, and considering the above, could be linked to either slaves or indentured labourers. This assumption should perhaps come as less of a surprise when we consider the accounts of how horrific the treatment of indentured labourers could be. At one stage, the evidence for abuse provoked the Indian government to halt recruitment for several years (Carter 1995).

\section{From slavery to indentured labour in Mauritius}

Slave trading was abolished in the British Empire in 1807, with the 'Slavery Abolition Act' bringing slavery itself to an end in 1833. The practice was outlawed in Mauritius in 1835 (Allen 2003). This closed a period in the island's past that has received scant attention from the archaeological community, despite important historical research indicating that the island had a large slave community (Aderibigbe 1989; Teelock 1998; Allen 2008; 2010), sourced from diverse labour markets by three colonial powers (Allen 2014; Nagapen 1996). History has also highlighted the reaction to abolition on the island specifically (Barker 1993; 1996), the influence that the slave population has had on modern Mauritius (Vaughan 2005, 174, 202-06), as well as the actions of maroons (Alpers 2003; Nagapen 1996) and reaction of European masters to this runaways (Allen 1999, 35-79). Slavery on Mauritius, as a distinct iteration of forced labour, serves as an important case study for the wider Indian Ocean and a significant comparative to the Atlantic. Furthermore, the island had a significant role in postslavery, 'free' or contract, labour.

Abolition was met with outcry by the French plantocracy on the island being very aware of the impact this would have on their highly lucrative sugar production. Financial concessions were made to placate the elite and prevent a potentially volatile situation. However, how would labour requirements be met in order to continue sugar production? The situation is a complicated one, but effectively, Mauritius, which had witnessed successive waves of forced labour since the Dutch first settled the island at Fort Frederik Hendrik (Floore and Jayasena 2010) in 1638 (they first reached Mauritius in 1598), now became the test case for indenture. Britain commenced its 'Great Experiment' in 1836 to replace slaves with ostensibly free labour. This notable chapter in the island's history was commemorated in 2006 with the inscription of the UNESCO World Heritage Site at Aapravasi Ghat, an immigration depot, through which almost half a million labourers came to the island (Carter 1995). These contract workers derived largely from Asia, predominantly from the
Indian subcontinent. The life they found themselves in was little more than slavery (Allen 1999; Teelock 2001; Drescher 2004); it would appear that potentially, this was at times complete with the shackle.

\section{The Trianon shackle: a description}

The Trianon shackle consists of three main features: a Dshaped bar, an eyelet and a hinge. An illustration of the artefact can be seen in Fig. 5, and a photograph highlighting details can be seen in Fig. 6. The shape of the artefact has a maximum length of $60 \mathrm{~mm}$ and a maximum width of $50 \mathrm{~mm}$. The widest part of the bar is $12 \mathrm{~mm}$ wide at the eyelet. The main feature of the artefact, the bar, is consistently $10 \mathrm{~mm}$ wide and $7 \mathrm{~mm}$ thick, except slight tapering towards the terminals. From the eyelet to the mid-point of the D-shaped bar, the section of the bar is rectangular with rounded sides. From this mid-point to the hinge, the section becomes pentagonal with distinctive planes and more angular corners.

The features described can best be attributed to a restraining device, in this case, a shackle. The artefact itself represents an incomplete shackle, consisting only of the Dshaped bar. The D-shaped bar has an eyelet at one end and parts of the pivotal hinge at the other. The term 'shackle' appears more frequently in the literature than other names given to the same device (fetters, leg irons or leg cuffs,

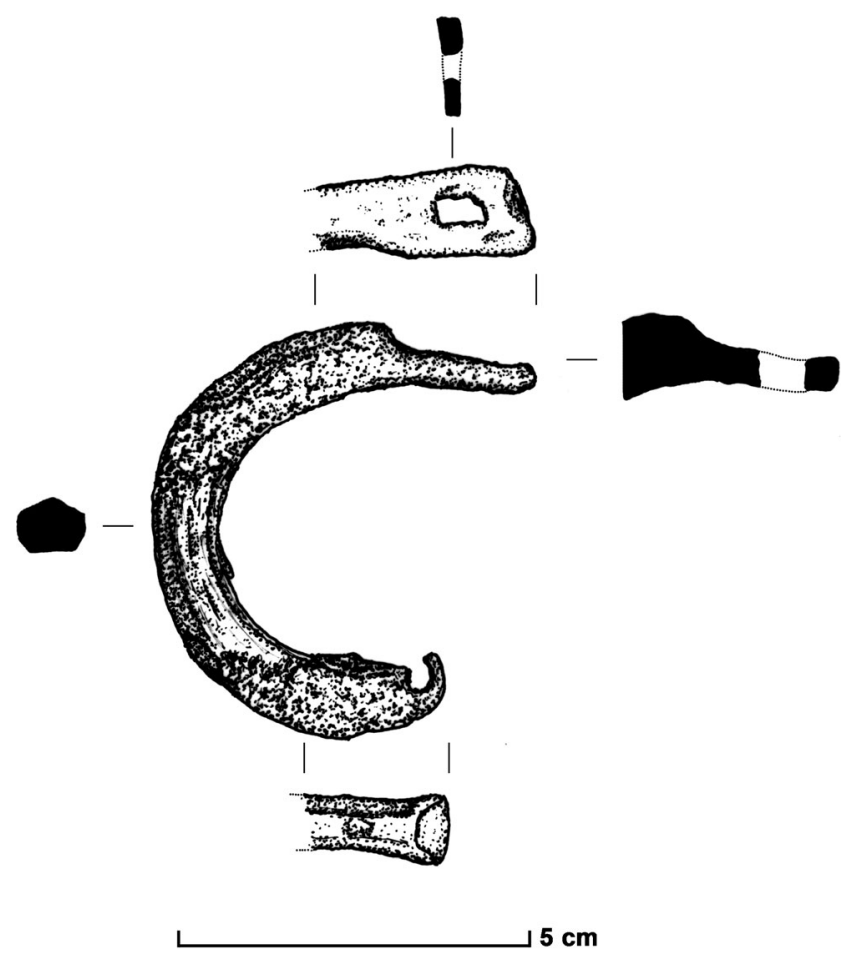

Fig. 5 Illustration of the shackle showing detail of the eyelet and hinge ends of the D-shaped bar and section profiles of the bar and eyelet were indicated 
Fig. 6 Photographs of the shackle, showing both profiles of the object, with close-up images of the eyelet and hinge sections from both the interior and exterior perspectives

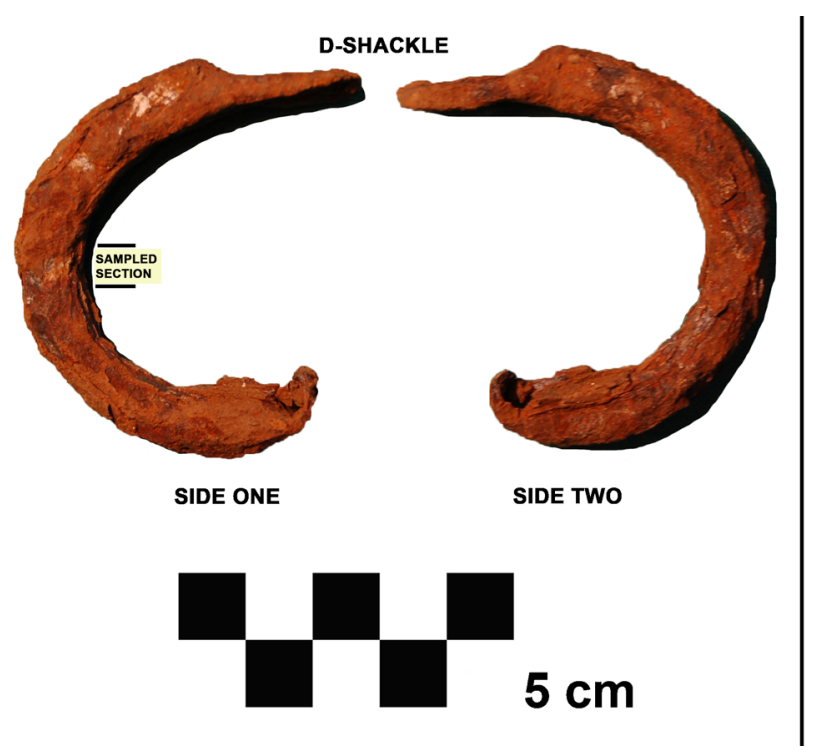

entraves and manacles) and so is adopted here. Bilboes are another similar device, though distinctly different in their form and mechanics.

Very little appears to have been published on 'shackles' or restraints, in general, relevant to historical and archaeological investigations. Thompson's (1993) study of Iron Age and Roman shackles is worthy of note, as is Malcom's (1998) short investigation of the bilboes recovered from an English slave ship. However, the only work relevant to the period under investigation here is Robin's (2007) collection of European-made restraints from the seventeenth to nineteenth centuries. The characteristic D-shape bar, lock mechanism (as inferred by the eyelet) and hinge are typical of European restraints from this period.

\section{Methodology}

The shackle was first studied, recorded and documented, upon which a single sample was obtained from the mid-section of the D-shaped bar (Fig. 6), using a water-lubricated rotary silicon carbide ( $\mathrm{SiC})$ grinder cutoff machine. The sample was then prepared as a standard metallographic block, mounted in a two-component epoxy resin before being ground and flatly polished to a $0.25-\mu \mathrm{m}$ finish.

The composition of the metal phase and the entrapped slag inclusions (SIs) was determined using an ISIS ABT-55 scanning electron microscope equipped with an Oxford Link Analytical AN 10/55S energy dispersive spectrometer system (SEM-EDS). Measurements were performed with a $15-\mathrm{kV}$ accelerating voltage with a $\approx 40 \%$ deadtime.

The precision and accuracy of the instrument used in this study was tested through repeated analysis of reference materials relevant to the study of slag (see Table 1).
Three basaltic reference glasses from the United States Geological Survey (USGS) were analysed (BCR-2G, BHVO-2G and BIR-1G). The low standard deviations $(\leq 0.2$ but more often around 0.1$)$ and the low relative quantification errors for major oxides (below $5 \%$, average $=2.7 \%$ ), with the exception of soda, reveal the instrument to have good accuracy and precision. It is good for quantifying concentrations to around $0.2 \mathrm{wt}$ \%, where the error for minor oxides is between 10 and $15 \%$ (average $=$ $11.9 \%$ ), whilst the error increases to around $20 \%$ for element concentrations at around 0.1 wt. \%, revealing good detection limits for this SEM-EDS system. The calibration of the scanning electron microscope was based on pure elements and simple compounds. Oxygen was not measured in this study but was calculated based on stoichiometry. All results are reported as averages and expressed in weight percent of the element oxides for SIs and expressed as pure elements for the analysis of the metal phase. Ten SIs were analysed, as were five area analyses of the metal phase, using SEM-EDS.

A metallographic study was performed on after the chemical analyses, etching the sample with nital and using a metallographic optical microscope in plane polarised light (PPL) to assess the microstructure and distinguish the different zones of interest. All micrographs are provided with scale bar (in micrometres) and microscope magnification $(\times 200$ and $\times 500)$. This order of techniques was adopted due to the affects of the etchant on the metal phase and SIs. The carbon coating from SEM-EDS was removed by polishing before etching. The sample was etched using $1 \%$ nital solution following wellestablished guidelines (Petzo 1978). The sample was studied and recorded optically. All sample preparations and analyses were performed at the University of Aberdeen. 
Table 1 Results from precision and accuracy testing performed on USGS basaltic glasses BCR-2G, BHVO-2G and BIR-1G

\begin{tabular}{|c|c|c|c|c|c|c|c|c|c|c|c|c|}
\hline & & $\mathrm{Na}_{2} \mathrm{O}$ & $\mathrm{MgO}$ & $\mathrm{Al}_{2} \mathrm{O}_{3}$ & $\mathrm{SiO}_{2}$ & $\mathrm{P}_{2} \mathrm{O}_{5}$ & $\mathrm{~K}_{2} \mathrm{O}$ & $\mathrm{CaO}$ & $\mathrm{TiO}_{2}$ & $\mathrm{MnO}$ & $\mathrm{FeO}$ (total) & $\mathrm{BaO}$ \\
\hline BCR-2G & Cert. & 3.2 & 3.56 & 13.4 & 54.4 & 0.37 & 1.74 & 7.06 & 2.27 & 0.19 & 12.4 & 0.076 \\
\hline \multirow[t]{4}{*}{$n=21$} & Anal. & 3.1 & 3.39 & 13.3 & 54.9 & 0.30 & 1.86 & 7.35 & 2.45 & 0.22 & 13.1 & 0.061 \\
\hline & STDev. & 0.2 & 0.1 & 0.1 & 0.2 & 0.1 & 0.0 & 0.1 & 0.1 & 0.1 & 0.2 & 0.1 \\
\hline & $\delta$ abs. & 0.1 & 0.17 & 0.1 & 0.5 & 0.07 & 0.12 & 0.29 & 0.18 & 0.03 & 0.7 & 0.015 \\
\hline & $\delta$ rel. $(\%)$ & 3.2 & 4.7 & 1.1 & 0.8 & 18.7 & 7.2 & 4.2 & 7.9 & 15.1 & 5.5 & 20.3 \\
\hline BHVO-2G & Cert. & 2.4 & 7.13 & 13.6 & 49.3 & 0.29 & 0.51 & 11.4 & 2.79 & 0.17 & 11.3 & 0.015 \\
\hline \multirow[t]{4}{*}{$n=21$} & Anal. & 2.2 & 6.80 & 13.3 & 50.5 & 0.18 & 0.53 & 11.7 & 2.90 & 0.19 & 11.5 & 0.067 \\
\hline & STDev. & 0.2 & 0.1 & 0.1 & 0.2 & 0.1 & 0.0 & 0.1 & 0.1 & 0.1 & 0.2 & 0.1 \\
\hline & $\delta$ abs. & 0.2 & 0.33 & 0.3 & 1.2 & 0.11 & 0.02 & 0.3 & 0.11 & 0.02 & 0.2 & 0.052 \\
\hline & $\delta$ rel. $(\%)$ & 8.3 & 4.6 & 2.2 & 2.4 & 36.5 & 3.8 & 3.1 & 3.9 & 12.3 & 2.1 & 349.9 \\
\hline BIR-1G & Cert. & 1.85 & 9.4 & 15.5 & 47.5 & 0.027 & 0.03 & 13.3 & 1.04 & 0.19 & 10.4 & 0.001 \\
\hline \multirow[t]{4}{*}{$n=21$} & Anal. & 1.81 & 9.0 & 15.2 & 48.3 & 0.001 & 0.06 & 13.6 & 1.03 & 0.21 & 10.6 & 0.023 \\
\hline & STDev. & 0.1 & 0.1 & 0.2 & 0.2 & 0.0 & 0.1 & 0.1 & 0.1 & 0.1 & 0.2 & 0.0 \\
\hline & $\delta$ abs. & 0.04 & 0.4 & 0.3 & 0.8 & 0.026 & 0.03 & 0.3 & 0.01 & 0.02 & 0.2 & 0.022 \\
\hline & $\delta$ rel. $(\%)$ & 2.4 & 4.0 & 1.9 & 1.7 & 96.6 & 111.2 & 2.6 & 0.7 & 8.3 & 2.4 & 2168.2 \\
\hline
\end{tabular}

The four rows for each reference glass present the certified values of the reference material ("Cert."), the normalised results of the mean of 21 SEM-EDS area measurements of the three reference glasses ("Anal."), the standard deviation for those three measurements ("STDev"), the absolute difference between the analyses and reference values for each compound (" $\delta$ abs.") and the relative difference between the analysed and the reference values for each compound expressed in percent (" $\delta$ ref. (\%)"). All oxides are in weight percent (wt. \%). The average analytical raw total from all the USGS basaltic glass analyses was $97.7 \mathrm{wt} \% \pm 0.7$ (1 standard deviation); the lower analytical total is reflective of analysing total iron contents as iron (II) rather than iron (III) oxide ( $\mathrm{FeO}$, rather than $\mathrm{Fe}_{2} \mathrm{O}_{3}$ )

$b d$ below detection limits

\section{Results}

\section{Slag inclusion analysis}

The entrapped SIs are multi-phased (Figs. 7 and 8), comprising of a fine-lathed fayalitic matrix and interstitial glass, with wüstite (mostly primary dendrites or globular). Ten SIs were large enough for SEM-EDS analysis (Table 2). The compositions of SIs are rich in phosphorous, at around $10 \mathrm{wt} . \%$ providing a strong indication that the iron originates from the indirect process. When SIs are plotted against known compositions of direct and indirect produced irons, after Dillman and L'Héritier (2007) bivariate scatterplot, it becomes clear that the iron derives from a blast furnace. This is further supported by the slightly elevated and noticeable levels of sulphur (around 0.8 wt. \%), which often are much lower in bloomery iron. The relatively small amounts of non-reduced compounds in the SIs composition would also indicate that the material was formerly cast iron, produced in the blast furnace.

\section{Iron analysis}

Five locations were randomly analysed in the iron phase (Table 3), consistently showing small amounts of phosphorous (around $0.2 \mathrm{wt}$ \%) in the metal. No other alloying components were detected. Although not a definitive characteristic, phosphorous is often associated with and detected in cast iron. Carbon content was judged optically to be approximately $0.1-0.15 \%$, as indicated by the microstructure, which would classify the material as a low-carbon steel.

\section{Macrostructure}

When viewed macroscopically, the brightness of the ferrous metal is a general indicator of carbon distribution, with highcarbon steel correlating with bright (almost white) areas and dark grey corresponding with pure ferritic iron (carbon-free). Mid-tones within this range, from white to dark grey, reflect the intermediate carbon content, with gradients and sharp boundaries reflecting the depth and diffusion patterns of any carburisation/decarburisation, as well as possible weld seams. The etched sample revealed a uniform dark grey appearance. No features indicative of weld seams, inclusions or differential carbon distribution could be observed. The appearance is consistent with a homogeneous iron or low-carbon steel.

\section{Microstructure}

The shackle's microstructure consists of the predominating metallic phase, containing a second phase of entrapped SIs (Figs. 7 and 8). The metallic phase consists almost entirely of ferrite, with very little interstitial pearlite (hypo-eutectoid 

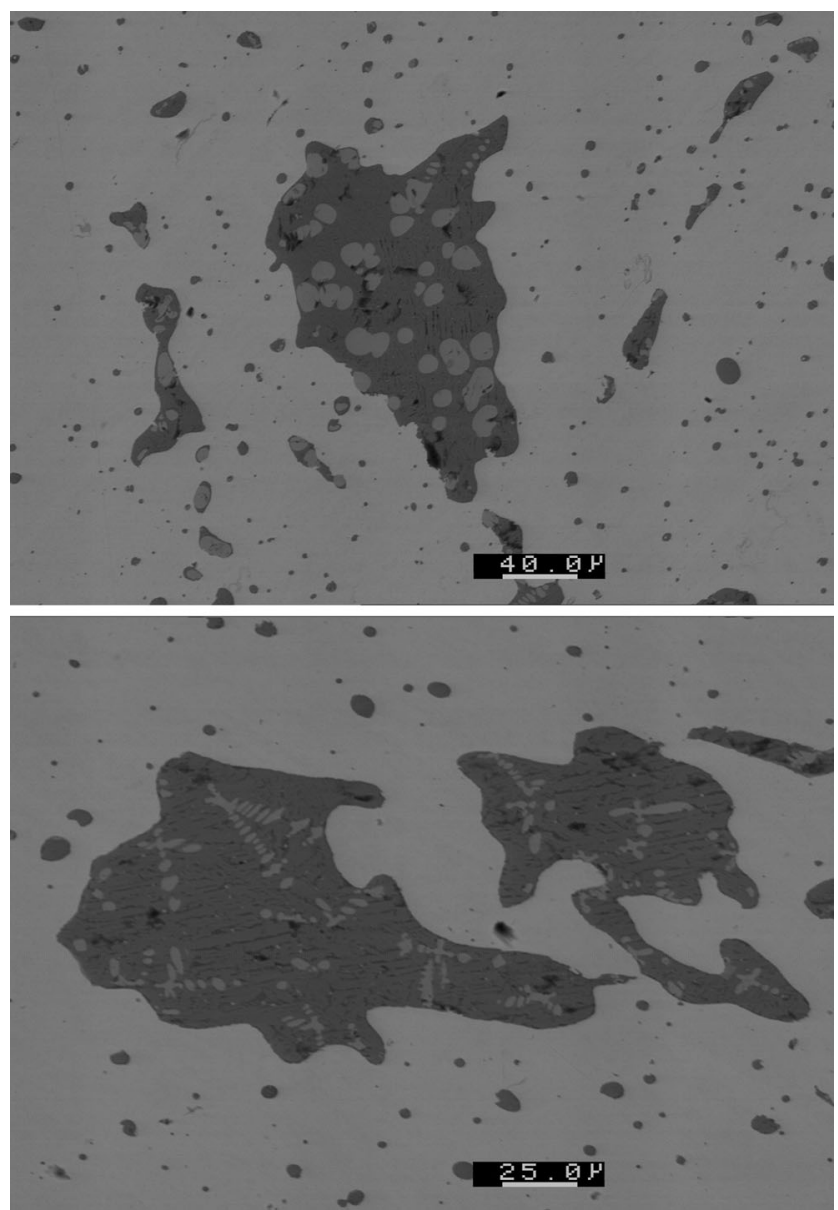

Fig. 7 Backscattered electron images of multi-phased SIs entrapped within the iron (scale in micrometres)

structure), confirming the iron to contain approximately $0.1-$ $0.15 \%$ carbon (Fig. 9). The carbon content, however, could be underestimated due to the prevalence of spheroidised carbides

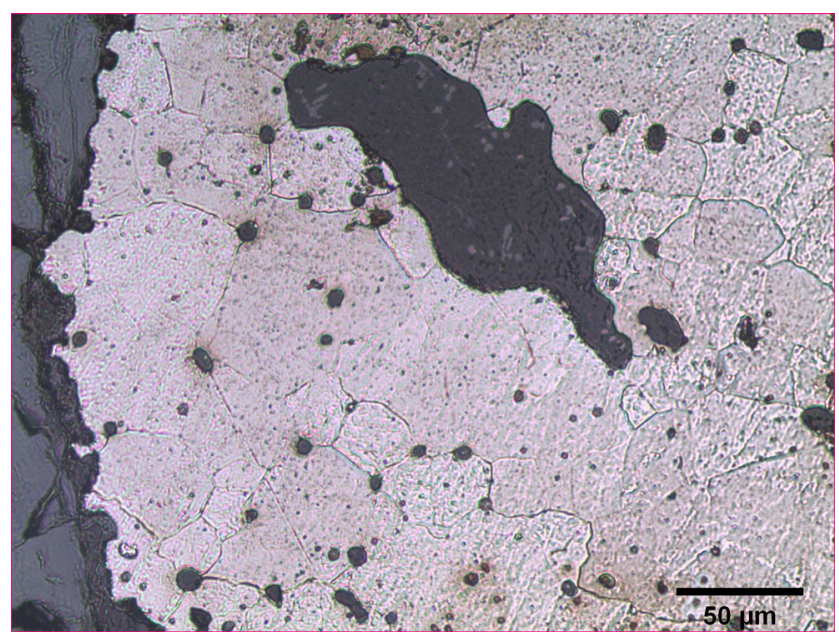

Fig. 8 Relatively homogeneous matrix consisting of hexagonal equiaxed grains of ferrite (pale white) and spherodised carbides (dark dots), containing one large and several small SIs (dark grey), with a layer of iron oxide corrosion (light grey) and slag (dark grey) at the surface (left of image). $P P L, \times 200$ visible in the ferrite. Spheroidised carbides represent the spheroidisation of pearlitic cementite that has 'balled up' and become granular (Figs. 8, 9, and 10).

Three types of grain structures can be observed. The predominating form is remnant equi-axed grains of ferrite (idiomorphic ferrite), which show clear deformation and are almost rounded in some areas (Fig. 9). Austenite boundaries can be made out in some instances where allotriomorphic ferrite has nucleated along the former surfaces. The low-carbon content allows the allotriomorphs to form. Widmanstätten structures (Fig. 11) can be identified amongst the majority of allotriomorphic ferrite, representing the areas richer in carbon $(0.15 \% \mathrm{C})$. The core of the shackle consists almost entirely of ferrite, with the interstitial pearlite increasing towards the surfaces of the artefact.

\section{Interpretation: technological origin and manufacture}

Phosphorus in steel promotes the ability to draw the iron, increases hardness and helps dissolve the carbon. The increased workability of the mild steel, in drawing, may indicate a reason why this material was selected for the manufacture of the shackle. Assuming that the bar is not cast, the phosphorus would promote drawing of the low-carbon steel into a bar/rod prior to being worked.

Slag inclusion analysis has become a more common tool in the study of ferrous materials, with particular interest in aspects of provenance and technology. In the last few decades, studies into ferrous metallurgy in archaeology have attempted to distinguish between the two processes used to make iron (Tholander 1989; Rostoker and Dvorak 1990; Buchwald and Wivel 1998; Starley 1999). One useful indicator for distinguishing between both processes is the relative amount of phosphorus. The metal phase and SIs in refined pig iron appear to contain significantly elevated levels of phosphorus, compared to bloomery iron. This has been shown in several studies (Starley 1999; Dillman and L'Héritier 2007).

The elevated levels of phosphorus in both the metal and slag phases are a strong indication that the low-carbon steel originated from the indirect process. Cast iron produced from a blast furnace would have been decarburised in a finery forge, where entrapped SIs would have become enriched in phosphorous that oxidised from the metal phase. This fining process would help to explain the relatively high amounts of phosphorous observed in the SIs composition. The interpretation that this shackle was made using low-carbon steel from the indirect process is further supported by the elevated amounts of sulphur and the low concentrations of nonreducing compounds.

The carbon is fairly evenly distributed, except those areas in the core almost entirely made of ferrite. There are no 
Table 2 Normalised SEM-EDS data for the analysis of ten SIs in the sample

\begin{tabular}{cccccccccccccc}
\hline Analysis & $\mathrm{Na}_{2} \mathrm{O}$ & $\mathrm{MgO}$ & $\mathrm{Al}_{2} \mathrm{O}_{3}$ & $\mathrm{SiO}_{2}$ & $\mathrm{P}_{2} \mathrm{O}_{5}$ & $\mathrm{SO}_{3}$ & $\mathrm{~K}_{2} \mathrm{O}$ & $\mathrm{CaO}$ & $\mathrm{TiO}_{2}$ & $\mathrm{MnO}$ & $\mathrm{FeO}$ & $\mathrm{BaO}$ & $\mathrm{Total}$ \\
\hline 1 & bd & 1.8 & 1.5 & 17.8 & 10.5 & 0.5 & bd & 2.5 & 0.7 & 5.9 & 58.6 & bd & 103.0 \\
2 & $\mathrm{bd}$ & 1.8 & 1.9 & 17.8 & 11.0 & 0.6 & bd & 2.6 & 0.6 & 6.2 & 57.5 & bd & 104.5 \\
3 & 0.4 & 1.8 & 2.5 & 17.7 & 12.8 & 0.5 & bd & 2.6 & 0.5 & 6.2 & 55.1 & bd & 103.3 \\
4 & 0.3 & 1.6 & 2.1 & 18.0 & 10.9 & 0.7 & 0.1 & 2.6 & 0.6 & 6.3 & 56.9 & bd & 103.0 \\
5 & 0.5 & 2.0 & 1.3 & 18.7 & 11.2 & 0.6 & bd & 2.8 & 0.6 & 6.5 & 56.0 & bd & 103.5 \\
6 & 0.5 & 1.4 & 1.6 & 14.1 & 8.9 & 1.0 & 0.1 & 2.2 & 0.4 & 4.9 & 64.9 & bd & 103.8 \\
7 & 0.7 & 1.6 & 1.9 & 13.3 & 8.6 & 0.8 & 0.1 & 2.1 & 0.7 & 4.7 & 65.6 & bd & 104.1 \\
8 & 0.6 & 1.2 & 2.3 & 13.8 & 8.2 & 1.0 & bd & 2.1 & 0.4 & 4.4 & 65.9 & bd & 105.2 \\
9 & bd & 1.7 & 2.0 & 18.3 & 8.1 & 1.2 & 0.1 & 2.8 & 0.7 & 5.6 & 59.5 & bd & 103.9 \\
10 & 0.2 & 1.3 & 3.0 & 14.5 & 8.4 & 1.0 & 0.1 & 2.1 & 0.3 & 4.7 & 64.3 & 0.1 & 104.5 \\
Average & 0.5 & 1.6 & 2.0 & 16.4 & 9.9 & 0.8 & 0.1 & 2.4 & 0.5 & 5.5 & 60.4 & 0.1 & 103.9 \\
\hline
\end{tabular}

All elements are expressed as oxides (stoichiometrically) in weight percent. The total column gives the analytical total prior to normalization bd below detection limits

diffusion boundaries indicative of case hardening. The shackle could have been decarburised further during the annealing process. Alternatively, the stock used to make the shackle was completely decarburised originally and carburised slightly during the smithing process. The cast iron used to produce the low-carbon steel, from which the shackle was manufactured, would have been significantly decarburised prior to working.

The microstructure indicates that the shackle was annealed, allowing for recrystallisation, producing a relatively homogeneous matrix of equiaxed ferrite grains. The annealing process also caused the cementite to spheroidise, occurring at around $625-675{ }^{\circ} \mathrm{C}$, below the austenitising transformation range.

The Widmanstätten structure in the area richer in carbon indicates that the austenitising range $\left(730-770{ }^{\circ} \mathrm{C}\right)$ was reached partially but not long enough to transform the entire matrix. At this temperature, some of the carbides start dissolving, which may help explain some of the difficulties in identifying some of the plastically deformed pearlitic cementite. All these imply that there was some limited overheating

Table 3 Normalised SEM-EDS data for five area analyses of the metal phase of the sample

\begin{tabular}{clll}
\hline Analysis & $\mathrm{Fe}$ & $\mathrm{P}$ & Total \\
\hline 1 & 99.8 & 0.2 & 100.7 \\
2 & 99.7 & 0.3 & 101.4 \\
3 & 99.9 & 0.1 & 102.0 \\
4 & 99.8 & 0.2 & 101.5 \\
5 & 99.8 & 0.2 & 100.6 \\
Average & 99.8 & 0.2 & 101.2
\end{tabular}

All elements are expressed in weight percent. The total column gives the analytical total prior to normalization during forging. There are no structures to indicate that the shackle was quenched or cooled quickly. The structures identified indicate that the shackle was air cooled after annealing.

The D-shaped bar of the shackle shows flat planes indicative of hammer forging (see cross section and illustration in Fig. 5), where subtle variations are more representative of smithing rather than casting. The logical order of shaping and forming actions to manufacture this part of the D-shaped shackle would have been as follows, with subsequent annealing:

1. To draw out a bar/rod of low-carbon steel (or decarburise a pre-cast bar, perhaps also drawn out)

2. To hammer one end flat (eyelet)

3. To perforate the flat end, producing the eyelet

4. To cut the bar (if needed) and flatten the opposing end (hinge)

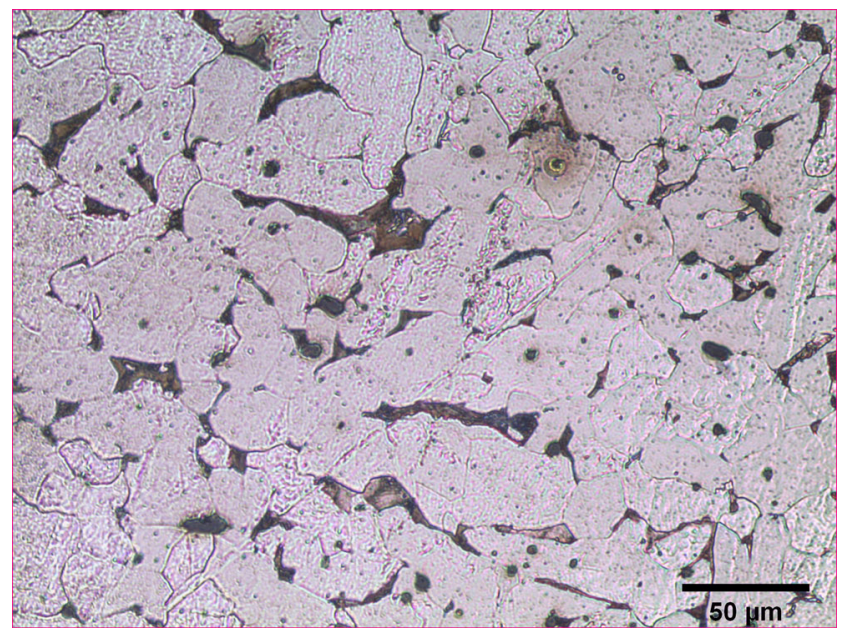

Fig. 9 Ferrite containing spheroidised carbides (dark spots), with interstitial pearlite (pale brown). PPL, $\times 200$ 


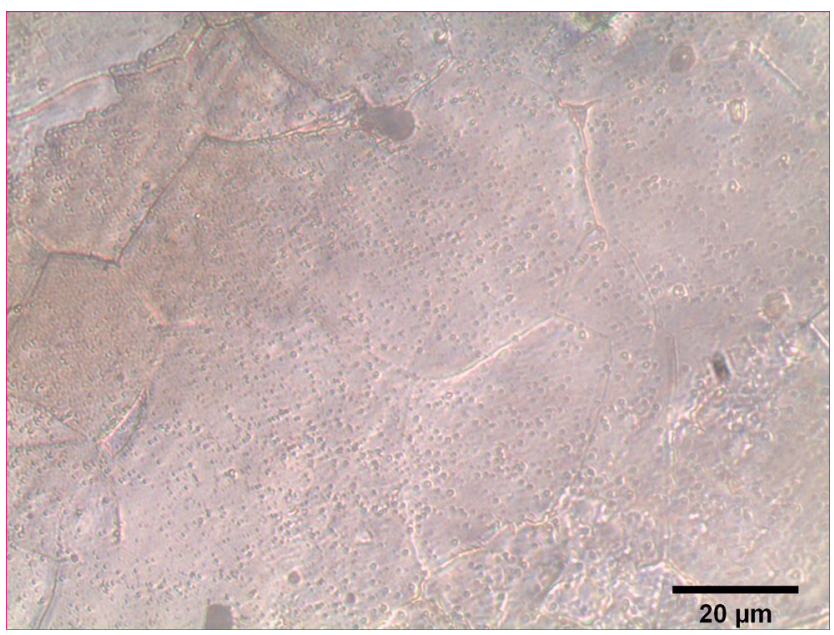

Fig. 10 Close-up image of the spherodised carbides (dark spots) within the ferrite. $P P L, \times 500$

5. To work the same flat end (hinge) back on itself, forming the pivotal hinge

6. And finally, shape the bar into a curve, producing the characteristic D-shape

\section{Discussion}

No studies are known, to the authors' knowledge, that have explicitly dealt with the issue of slavery and colonial ironwork in the southern hemisphere. While clearly a sensitive area of discussion, the present pilot project highlights a new opportunity to address this topic. The artefact exemplifies a range of issues that have remained virtually unstudied from the post-medieval Indian Ocean; while the movement of 'goods' has emphasised spices, ivory and chattel (i.e. slaves), we know very little about

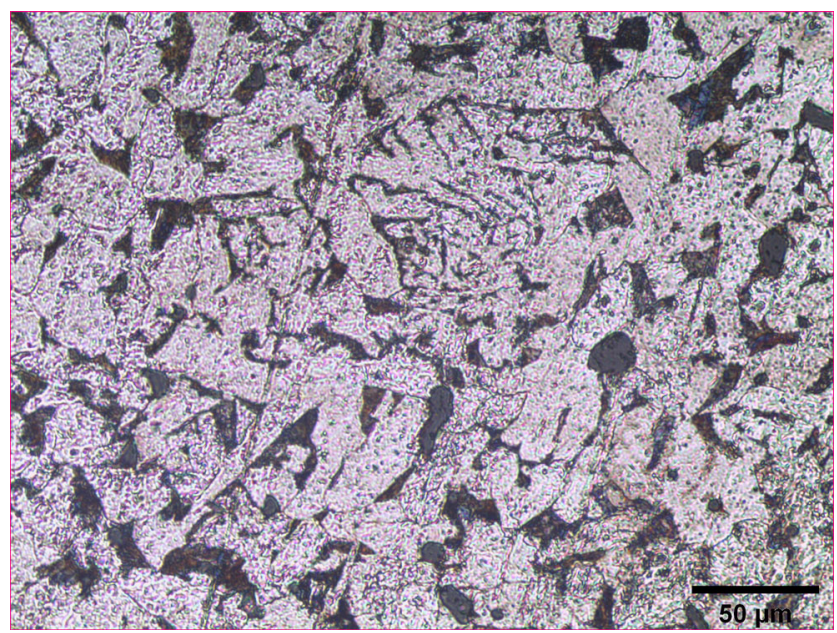

Fig. 11 Mostly allotriomorphic ferrite (equi-axed and rounded grains) and pearlite, with some Widmanstätten ferrite (acicular grains, white). $P P L, \times 200$ the provisioning of everyday products, such as iron. Such assessments are no less valuable when one considers their technological role and subsequent place in social development. Here, we add important details as to the processes that underpinned the formation of such objects and present an opportunity for this artefact to be compared both within and beyond the Indian Ocean basin in future studies.

One issue, at least circumstantially, that we have been able to shed light on is the question of provenance. The authors were aware that discovering an accurate provenance for the iron used to make the shackle would be complicated by the fact that there are no comparative sites, and therefore no reference data (production sites), against which to compare and contrast our results, as well as the issues associated with the difficulty in provenancing iron from the indirect process. From our findings, however, it is possible to postulate that the low-carbon steel was produced by the indirect process, which is most often associated with blast furnaces in Europe. As there is no evidence for blast furnace technology on Mauritius, the low-carbon steel used to manufacture the shackle must have derived from elsewhere. Europe seems the likely and obvious location; however, even if Europe is the most plausible source, the maritime trade incorporated other regions with long traditions of iron production, such as East Africa (Childs and Killick 1993) or India (Hedge 1973). What is important here is that the steel is unlikely to have been produced in Mauritius. Incorporating the historical context, it seems most likely that the D-shaped shackle studied here represents colonial ironwork.

While it would be a mistake to overinterpret this artefact's role within the paradigm of slavery, we may suggest that it was an object associated with forced labour, not free. This is based on the fact that slaves were utilised at Trianon for a significant portion of the time that it functioned as a sugar estate, and that the barracks themselves may have housed slaves, with labourers preferring thatch huts. Thus, we may tentatively add this artefact to the impoverished cohort of objects associated with slavery (if not in actuality a 'slave' object per se) (Handler 2009).

However, clearly, we cannot rule out the possibility that this shackle may have been used to restrain free labourers after abolition. From the viewpoint of 'the human experience of indenture', one might assume that such a find is remarkable. However, as well described in the historic literature on the subject, indenture mimicked many features of slavery, although the mode of expression differed. The poor treatment that both slave and labourer received prompted both groups to run away from the plantation. During the slave period, this was termed marronage (Nagapen 1999); for the indentured labourer, the equivalent was vagrancy (Allen 2004). If caught, 
the punishment for the slave was severe in the extreme; for the labourer, corporal punishment could be meted out, as well as imprisonment (Deerpalsingh 2004). Indeed, the Vagrant Depot in Grand River North West was established specifically for this purpose, as the smaller prisons on the island were unable to deal with the large number of runaway labourers (Peerthum 2004). Thus, the shackle had a place during this ostensibly enlightened period as a mechanism of control. While this find is certainly informative, intriguing and potentially motivates new lines of enquiry, we should perhaps be less surprised to observe such an artefact on a site that was primarily inhabited by labourers. Furthermore, we should be cautious and avoid viewing its function as being synonymous with the use of such devices during the slave period. While they clearly serve the role of a restraint, it is likely that their use was fundamentally different, for example, in terms of length of time an individual spent in them.

Thus, the present article has raised more questions than it has answered, as is typical of pilot studies. These questions relate to the diverse material culture associated with labour migration, the treatment of slaves and labourers and the likely circumstances of their lives. At a more pragmatic level, future research could address whether such restraints were used for the hands or feet? On a more profound level, this type of artefact forces us to question changing perceptions. How might archaeological studies in the future, focused on objects such as this shackle, lead to a clearer understanding of the way the workforce was viewed by the plantation owners? How did attitudes change with the advent of indenture, considering the freedoms that contract workers were ostensibly entitled too, i.e. in some cases to select where to erect their homestead, as well as undertake their own cooking (effectively retaining an aspect of their culture)? How were these freedoms balanced and negotiated against attitudes that demanded firm action to deal with vagrancy and potentially, resulted in the use of physical restraints?

As historical archaeology in the region flourishes, such studies are likely to form the basis of major insight into this complex region. This artefact provides the impetus for important research questions that draw on archaeological and historical sources. The latter have, to date, dealt almost exclusively with the details of the labour diasporas that characterise the region. The strength of archaeology lies in providing a more nuanced perspective, which is critical if we are to better understand the decisions of the imperial powers and day-today life on these colonial enclaves.

Acknowledgments Funding for this research has been provided by and gratefully received from the Aapravasi Ghat Trust Fund (AGTF), The British Academy, The British Council, The McDonald Institute for Archaeological Research and the University of Central Lancashire (UK). The authors gratefully acknowledge the support of Dr. Vijaya Teelock, Ms. Corinne Forrest, Mr. Renganaden Andiapen and Mr. Satyendra Peerthum from the AGTF; Dr. Anwar Janoo and students from the
University of Mauritius; and to Rose Ferraby, Branko Mušič, Igor Medarič and Matjaž Mori for their geophysical reconnaisance. The work was conducted with the help of technician John Still at the University of Aberdeen. The authors also wish to thank the two anonymous reviewers for their constructive feedback, which has been incorporated into the final version of this article.

Author contributions The analysis and metallographic study of the Trianon shackle were conducted by Thomas Birch, who drafted the manuscript jointly with Krish Seetah. Diego Calaon and Saša Čaval led the fieldwork and excavations at Trianon as part of the MACH project, led by Krish Seetah, and provided commentary and illustrations for the article.

\section{References}

Aderibigbe AB (1989) Slavery in south-west of Indian Ocean, in Slavery in the South West Indian Ocean, ed. U Bissoondoyal \& SBC Servansing. Mahatama Gandhi Institute: Moka 320-30

Allen RB (1999) Slaves, freedmen and indentured laborers in colonial Mauritius. Cambridge University Press, Cambridge

Allen RB (2003) The Mascarene slave-trade and labour migration in the Indian Ocean during the eighteenth and nineteenth centuries. Slavery Abolit 24:33-50. doi:10.1080/01440390308559154

Allen RB (2004) Vagrancy and labour control in mid-nineteenth century Mauritius, 1834-1875, in The vagrant depot of Grand River, its surroundings and vagrancy in British Mauritius, ed. V Teelock. Port Louis, Aapravasi Ghat Trust Fund, pp 35-46

Allen RB (2008) The Mascarene slave-trade and labour migration in the Indian Ocean during the eighteenth and nineteenth centuries. Slavery and Abolition 24:33-50

Allen RB (2010) Satisfying the 'want for labouring people': European slave trading in the Indian Ocean, 1500-1850. Jof World History 21(1):45-73

Allen RB (2014) European slave trading in the Indian Ocean, 1500-1850. Ohio University Press, Athens

Alpers EA (2003) Flight to freedom: escape from slavery among bonded Africans in the Indian Ocean world, c. 1750-1962. Slavery and Abolition 24:51-68

Appleby J, Seetah K, Calaon D et al (2014) The juveni Athens le cohort from Le Morne cemetery: a snapshot of early life and death after abolition. Int J of Osteoarch 24:737-746

Barker AJ (1993) Distorting the record of slavery and abolition: the British anti-slavery movement and Mauritius, 1826-37. Slavery and Abolition 14:185-207

Barker AJ (1996) Slavery and antislavery in Mauritius 1810-33. St. Martins Press, New York

Buchwald VF, Wivel H (1998) Slag analysis as a method for the characterization and provenancing of ancient iron objects. Mater Charact 40:73-96

Calaon D, Čaval S, Morales-Matoes J, Seetah K (2012) Archaeological insights into the "indentured experience": the case of Trianon barracks. In: Teelock V (ed) Angage Explor. Hist. Soc. Cult. Indentured Immigr. Their Descend. Maurit. Aapravasi Ghat Trust Fund, Port Louis, pp 121-138

Carter M (1995) Servants, sirdars, and settlers: Indians in Mauritius, 1834-1874. Oxford University Press, Delhi and New York

Childs ST, Killick D (1993) Indigenous African metallurgy: nature and culture. Annu Rev Anthropol 22:317-337. doi:10.2307/2155851

Colwell-Chanthaphonh C, Le Chartier S, Jacquin-Ng S (2014) The search for Makak: a multidisciplinary settlement history of the northern coast of Le Morne Brabant, Mauritius. Int J of Hist Arch 18(3): $375-414$ 
Deerpalsingh S (2004) An overview of vagrancy laws, its effects and case studies, 1860-1911. In: Teelock V (ed) Vagrant Deport Gd. River Its Surround. Vagrancy Br. Maurit. Aapravasi Ghat Trust Fund, Port Louis, pp 47-83

Dillman P, L'Héritier M (2007) Slag inclusion analyses for studying ferrous alloys employed in French medieval buildings: supply of materials and diffusion of smelting processes. J Archaeol Sci 34:1810 1823

Drescher S (2004) The mighty experiment: free labour versus slavery in British emancipation. Oxford University Press, New York

Floore PM, Jayasena RM (2010) In want of everything? Archaeological perceptions of a Dutch outstation in Mauritius (1638-1710). Postmed Arch 44(2):320-40

Gosden C (2004) Archaeology and colonialism. Culture contact from $5000 \mathrm{BC}$ to the present. Cambridge University Press, Cambridge

Handler JS (2009) The middle passage and the material culture of captive Africans. Slavery and Abolition 30:1-26

Hedge KTM (1973) Understanding ancient Indian iron metallurgy. Man $83: 416-421$

Malcom C (1998) The iron bilboes of the Henrietta Marie. Navig. Newsl. Mel Fish. Marit. Herit. Soc. Vol 13, No. 10

Nagapen A (1996) Histoire de la Colonie: Isle de France-Ile Maurice 1721-1968. Port-Louis, Diocèse de Port-Louis

Nagapen A (1999) Le marronnage à l'Isle de France-Ille Maurice: rêve ou riposte de l'esclave? Port-Louis, Centre Culturel Africain

Orser CE Jr (2014) A primer for modern-world archaeology. Eliot Werner Publications, New York

Peerthum S (2004) A history of the Vagrant Depot of Grand Rivers North West, 1864-1886. In: Teelock V (ed) Vagrant Deport Gd. River Its Surround. Vagrancy Br. Maurit. Aapravasi Ghat Trust Fund, Port Louis, pp 84-119

Peerthum S (2010) History of the old labourers' quarter of trianon: a rare national point. Newsl Aapravasi Ghat Trust Fund 8(10):12

Petzo G (1978) Metallographic etching: metallographic and ceramographic methods for revealing microstructure. American Society for Metals, Metals Park, Ohio
Report Royal Commissioners of Immigrants, 1875 = Report of the Royal Commissioners Appointed to Enquire Into the Treatment of Immigrants in Mauritius: Presented to Both Houses of Parliament by Command of Her Majesty, 6th February, 1875, Volume 1, London, 1875

Robin J-M (2007) Entraves, fers \& menottes

Rostoker W, Dvorak J (1990) Wrought irons: distinguishing between processes. Archeomaterials 4:153-166

Rouillard G (1979) Histoire des domaines sucriers de l'Ile Maurice. General Print \& Stationery Co., Port Louis

Seetah K (2010a) Researching the everyday lives of indentured labourers: archaeological work at Trianon barracks. Newsl Aapravasi Ghat Trust Fund 8(11):14

Seetah K (2010b) "Our struggle". Mauritius: an exploration of colonial legacies on an island paradise. Shima Int J Res Isl Cult 4:99-112

Seetah K (2015a) Objects past: objects present Material signatures of ephemeral communities. J of Soc Arch 15:233-53

Seetah K (2015b) The archaeology of Mauritius. Antiquity 89:922-39

Seetah K, Balbo A, Calaon D et al (2011) The Mauritian Archaeology and Cultural Heritage Project: exploring the impact of colonialism and colonization in the Indian Ocean. Antiquity 85:330

Starley D (1999) Determining the technological origins of iron and steel. J Archaeol Sci 26:1127-1133

Teelock V (1998) Bitter sugar. Moka, Mahatma Gandhi Institute

Teelock V (2001) Mauritian history: from its beginnings to modern times. Mahatma Gandhi Institute, Moka, Mauritius

Tholander E (1989) Microstructure examination of slags as an instrument for identification of ancient iron-making processes. In: Pleiner $\mathrm{R}$ (ed) Archaeometall. Iron. Archaeometallurgy of Iron. International Symposium of the Comite' pour la Siderurgie Ancienne de L'UISPP, Prague, pp 35-41

Thompson H (1993) Iron age and roman slave-shackles. Archaeol J 150: $57-168$

Vaughan M (2005) Creating the Creole Island. Duke University Press, Durham 